\title{
The trend of HIV/AIDS prevalence among IDU's in Iranian prisoners (1376-1386)
}

\author{
Mohammad Shahbazi, Marziyeh Farnia, Ghobad Moradi, Bahman Ebrahimi \\ From $16^{\text {th }}$ International Symposium on HIV and Emerging Infectious Diseases \\ Marseille, France. 24-26 March 2010
}

\section{Background}

Prisons are recognized worldwide as important sites for transmission of blood-borne viruses (BBVs). the high prevalence of HIV infection and drug dependence among prisoners, combined with the sharing of injecting drug equipment, make prisons a high-risk environment for the transmission of HIV and the lack of supply of preventive measures (such as sterile needle and syringes or condoms or methadone maintenance therapy). In most prisons of world, because of a variety of social conditions, extra opportunities for BBV transmission are created.

HIV prevalence in Iran is generally more than 8 times higher in prisons (1.75) than in general population estimation (0.2) because of the considerable over-representation of injecting drug users (IDUs) among prisoners. We want to study the trend and outcome of interventions of HIV/AIDS in IDU's prisoners of Iran during 1997-2007.

\section{Methods}

Based on the HIV test outcome in prisons due to sentinel services during a 9-year period from 1997 to 2007, we used the data from all sentinel services in all prisons all over the country during this period. Annual HIV prevalence among prison inmates in Iran was determined and also major interventions during these times investigated.

\section{Results}

In an 11-year time period from 1997 to 2007, 107 sentinel services have been established among drug user prisoners, in which as a whole 42142 people were studied. Infection results during different years are as follow:

\footnotetext{
* Correspondence: mohamad.shahbazi@yahoo.com

GFATM(theglobalfund.org) - Iran Prisons Organization, Tehran, Iran, Islamic Republic of
}

- 1997, prevalence rate 0.15 percent, $\mathrm{CI}=(0.13,0.16)$ and number $(3 / 2022)$

- 1998 , prevalence rate 0.30 percent, $\mathrm{CI}=(0.28,0.31)$ and number $(7 / 2367)$

- 1999, prevalence rate 0.48 percent, $\mathrm{CI}=(0.46,0.50)$ and number $(8 / 1670)$

- 2000 , prevalence rate 3.17 percent, $\mathrm{CI}=(3.07,3.27)$ and number $(2553 / 81)$

- 2001, prevalence rate 2.17 percent, $\mathrm{CI}=(2.13,2.22)$ and number (99/4556)

- 2002, prevalence rate 4.01 percent, $\mathrm{CI}=(3.92,4.10)$ and number $(236 / 5881)$

- 2003, prevalence rate 3.39 percent, $\mathrm{CI}=(3.31,3.47)$ and number (153/4515)

- 2004, prevalence rate 4.11 percent, $\mathrm{CI}=(3.99,4.22)$ and number (157/3824)

- 2005 , prevalence rate 4.86 percent, $\mathrm{CI}=(4.74,4.98)$ and number $(239 / 4920)$

- 2006, prevalence rate 2.99 percent, $\mathrm{CI}=(2.92,3.05)$ and number $(157 / 5226)$

- 2007, prevalence rate 2.34 percent, $C I=(2.29,2.39)$ and number (107/4571)

Two important and effective interventions performed in Iran prisons in this time period include:

1. Initiation and extending substance methadone therapy in such a way that its coverage improved from 300 prisoners in 2003 to 19500 prisoners in 2007.

2. Another important intervention was the establishment of triangular clinics (voluntary counseling testing) in Iran prisons. It started with the coverage of 1 in 2001 and reached the coverage of 105 in 2007.

\section{Discussion}

The 11-year trend of HIV among Iranian prisoners showed that although the prevalence was low in the beginning years, it gradually got a rising trend and it reached its pick of 4.86 percent in 1384 and then it 
started to decrease again. Although the last HIV prevalence rate among Iranian addicted prisoners was extremely more than general population of the country, its falling trend could be a symbol of effectiveness of performed interventions to decrease HIV prevalence. Therefore, two main intervention i.e. initiation of voluntary counseling \& testing centers and substance methadone therapy (MMT) that were used as AIDS control strategies in Iranian prisons were greatly suitable and efficient.

Published: 11 May 2010

doi:10.1186/1742-4690-7-S1-P101

Cite this article as: Shahbazi et al:: The trend of HIV/AIDS prevalence

among IDU's in Iranian prisoners (1376-1386). Retrovirology 2010

7(Suppl 1):P101.

Submit your next manuscript to BioMed Central and take full advantage of:

- Convenient online submission

- Thorough peer review

- No space constraints or color figure charges

- Immediate publication on acceptance

- Inclusion in PubMed, CAS, Scopus and Google Scholar

- Research which is freely available for redistribution 